\title{
Situs Hindu Pra-islam di Kudus dan Sikap Toleran Sunan Kudus
}

\author{
Moh Rosyid* \\ IAIN Kudus, Indonesia \\ Email: mrosyid72@yahoo.co.id
}

\begin{abstract}
Among historical sites in Kudus, Central Java is Langgar Bubrah, in which laying lingga and yoni, two symbols often found in a Hindu temple. Some archeologists consider this as proof of Sunan Kudus's tolerance. This paper analyzes the preservation of religious sites and their relation to promote religious tolerance. Data were collected through interviews, observation, and documentation analysis is descriptive qualitative. The result shows that Sunan Kudus promoted tolerance among his people by preserving several old traditions such as preventing. However, the Kudus Regency Government has optimized tried to treat it, so it needs to be scheduled to rescue cultural objects, namely restoration, revitalization, and facilitating cultural facilities and infrastructure in the form of performance spaces. Kudus local parliament members also need to realize the budget politics in the regional budget, which favors cultural preservation by providing funding for cultural advancement based on investment considerations. The research to contribution for development archeology associated with culture heritage Hindu in Kudus pra-Islam.
\end{abstract}

Keywords: Culture heritage; Sunan Kudus; tolerance.

\begin{abstract}
Abstrak
Di Kota Kudus, kawasan kota kunonya terdapat cagar budaya era Hindu pra-Islam yang lestari hingga kini. Ciri khas benda budayanya berupa lingga dan yoni yang masih lestari. Tulisan ini bertujuan mendedahkan fakta bahwa Sunan Kudus dan generasi muslimnya tidak mengubah dan merusak cagar budaya peninggalan umat Hindu pra-Islam di Kudus di Langgar Bubrah. Sikap tersebut kategori toleran sehingga nilai toleransinya oleh warga Kudus perlu dilestarikan. Teknik perolehan data dengan wawancara, observasi, dan pendalaman literatur dengan analisis deskriptif kualitatif. Hasil riset, Kota Kudus Jawa Tengah terdapat situs khas di antaranya bangunan kuno disebut Langgar Bubrah. Bangunan itu terdapat lingga dan yoni sebagai karakter candi yang dilestarikan hingga kini sebagai bentuk toleransi Sunan Kudus yang dilanjutkan oleh generasi muslim kini. Pemkab Kudus perlu optimal merawatnya sehingga diagendakan penyelamatan objek budaya yakni restorasi, revitalisasi, dan penganggaran. Kontribusi hasil riset ini untuk pengembangan kajian arkeologi terkait dengan peninggalan purbakala era Hindu pra-Islam di Kudus.
\end{abstract}

Kata Kunci: Cagar budaya, Sunan Kudus; toleransi.

\section{PENDAHULUAN}

Masa kini ada karena ada masa lalu, kedua masa tersebut berkesinambungan. Masa lalu dalam kajian sejarah bila berupa fakta data empiris tersebut dapat dijadikan kajian pokok dalam sejarah. Masa lalu dapat berupa ragam peninggalan bersejarah di antaranya situs sejarah. Adanya situs sebagai penanda bahwa masa yang telah berlalu terdapat pelaku sejarah yang mewariskannya pada generasi kekinian. Di Jawa Tengah, terdapat Kota Kudus yang mendapat ragam julukan, yakni kota santri (ratusan pondok pesantren dan kiai, ribuan santri da siswa), kota budaya (puluhan budaya khas Kudus), kota bersejarah, dan kota kretek. Masing-masing ikon dapat dijadikan kajian untuk memperkuat bahwa Kudus sebagai kota yang wilayahnya terkecil di Jawa Tengah mewarnai dinamika nasional.

Di Kota Kudus terdapat situs sebagai benda cagar budaya dan terdapat kekhasan sebagaimana peninggalan candi Hindu, warga Kudus memberi sebutan Langgar Bubrah (selanjutnya ditulis LB). LB 
Khazanah Theologia, Vol. 3 No. 3 (2021): 171-180

Situs Hindu Pra-islam di Kudus dan Sikap Toleran Sunan Kudus

Moh. Rosyid

merupakan bangunan kuno yang diduga dimanfaatkan untuk tempat ibadah umat Hindu di Kudus masa lalu dengan bukti terdapat lingga dan yoni. Lingga dan yoni merupakan bentuk benda yang berada di bangunan kuno di Kudus hingga kini. Akan tetapi, hal yang disayangkan, Pemkab Kudus kurang memberi perhatian. Dampaknya, lahan bangunan cagar budaya tersebut kian menyusut diduga 'kreatifnya' pemilik lahan di sekitar LB 'memanfaatkan' untuk perluasan halamannya dengan dipagar. Dugaan ini perlu dikaji perspektif hukum dengan melibatkan arkeolog dan Badan Pertanahan Nasional yang memiliki data pertanahan. Di sisi lain, benda peninggalannya banyak yang rusak karena minimnya perawatan seperti ornamen di LB yang sudah tidak nampak pernik-perniknya.

Cagar budaya (CB) dapat berupa benda CB, bangunan CB, struktur CB, situs CB, dan kawasan CB. CB harus dilestarikan karena CB memiliki kandungan makna penting untuk pengembangan ilmu pengetahuan khususnya arkeologi dan sejarah, kebudayaan, dan keagamaan. UU Nomor 11 Tahun 2010 tentang CB untuk menjadi pijakan hukum bagi publik dan penyelenggara negara bila merawat dan melestarikan peninggalan budaya bangsa. Awal mula diterbitkannya UU CB karena CB dipandang sebagai khazanah budaya bangsa dan perwujudan karya dan pemikiran anak bangsa. Konsekuensinya harus dilindungi, dikembangkan, dan dimanfaatkan untuk kemajuan budaya dan kesejahteraan rakyat. Pola pandangnya dengan melestarikan atas dasar pertimbangan aspek keilmuan, ideologi, dan ekonomi untuk kesejahteraan rakyat.

Kekhasan Kota Kudus memiliki peninggalan bersejarah berupa LB dan lestari sehingga muncul pertanyaan apakah lestarinya situs tersebut sebagai bukti Sunan Kudus dan generasinya hingga masa kini tetap melestarikan sebagai wujud toleran terhadap umat Hindu melalui peninggalannya? Logikanya, apabila tidak toleran, kemungkinan LB dimusnahkan. Tetapi, pelestariannya berhadapan dengan upaya pihak tertentu yakni (diduga) mengganti namanya menjadi Langgar Bubrah, bukan Sanggar atau Candi Bubrah. Langgar memiliki makna tempat ibadah bagi muslim atau tempat hunian. Dalam hal ini, bermakna tempat ibadah.

Para peneliti memiliki perhatian terhadap Kawasan Kota Kudus Kuno. Pertama, Roesmanto, Masjid al-Aqsha Kudus bentuknya serupa dengan bangunan Hindu, seperti candi di Jawa Timur antara lain Candi Kidal, Candi Jago, dan Candi Singasari. Keserupaan ini karena rupa dan bentuk Menara Kudus laksana bale yang memiliki konstruksi rangka kayu dan adanya kentongan yang menggantung di bagian atas, di bawah atap. Selain itu, memiliki bagian pejal yang tinggi sebagai penyangga bale (Roesmanto, 2013). Kedua, Supatmo, Masjid Menara Kudus memiliki fenomena unik berupa gaya menaranya serupa dengan candi Hindu. Seni bangunan kompleks Masjid al-Aqsha Menara Kudus adalah berkesinambungan dengan gaya seni Hindu-Buddha (pra-Islam) dipadu gaya seni bangunan Islam dan seni hias (ornamen) pendukungnya. Ornamen makhluk bernyawa (figuratif) yang melatarbelakangi kepercayaan dan budaya menghiasi bangunan. Bentuk ini tidak lazim dalam tradisi seni hias dalam Islam (Supatmo, 2014). Ketiga, Anisa, kawasan Kauman Menara Kudus merupakan kota lama atau cikal bakal Kota Kudus. Perekonomian warganya mempengaruhi tataruang kampung. Rumah tradisional Kudus berbentuk bangunan sisir wujud ruang khusus untuk aktivitas perekonomian. Rumah yang tidak terdapat bangunan sisir, aktifitas perekonomian di jogosatru (ruang digunakan untuk ruang publik) (Anisa, 2017). Karya para penulis tersebut mengkaji aspek tata ruang khas Kawasan Kauman Menara Kudus, sedangkan keberadaan LB di Kota Kudus ditelaah peneliti pula. Pertama, Himawan, bentuk Langgar Bubrah dibangun pada masa transisi dari Hindu-Buddha ke Islam sehingga nampak akulturasi pada mihrab (tempat berdoa) yang berwujud relung berada di bagian dinding sebelah luar. Relung ini dihiasi motif tetumbuhan sedangkan dindingnya (di sebelah tenggara) berupa relief seorang lelaki, rambutnya tertata rapi, posisinya berdiri serupa kepala sang Buddha. Di LB masih ada lumpang batu persegi panjang, panjangnya $95 \mathrm{~cm}$, lebarnya 
Khazanah Theologia, Vol. 3 No. 3 (2021): 171-180

Situs Hindu Pra-islam di Kudus dan Sikap Toleran Sunan Kudus

Moh. Rosyid

$45 \mathrm{~cm}$, tingginya $35 \mathrm{~cm}$, berbentuk sebagaimana batu pipisan (sarana pemujaan dan berfungsi penghalus biji-bijian). Difungsikan juga meramu jamu tradisional. Lumpang batu sebagai hasil karya budaya era Hindu-Buddha pra-Islam di Kudus (Himawan, 2012).

Kedua, inventarisasi Balai Pelestarian Cagar Budaya (BPCB) Jawa Tengah di kawasan Gunung Muria dari segi tinggalan arkeologi pada 26 Juli s.d 4 Agustus 2016 ditemukan di Dukuh Duplak Kecamatan Keling, Kabupaten Jepara meliputi Candi Angin, Candi Bubrah, Candi Aso, Kolam Batu di Sumur Batu, prasasti, arca terakota, dan artefak dan di Dukuh Petung ditemukan yoni dan arca di Punden Mbah Romban. Ditemukan pula fitur alam/cagar alam (geosites) berupa watu tumpuk di Dukuh Kemiren, watu gambang di perbatasan Duplak-Sumanding, tempuran kali/sungai di Dukuh Petung, lumpang/duplak di sumur batu di Dukuh Duplak. Ada pula data etnografi di Desa Tempur, Jepara berupa punden mbah Romban di Dukuh Petung, sumur batu/punden mbah Eyang Dhono di Dukuh Duplak, Punden mbah Robyong di Dukuh Duplak, punden Eyang Abiyoso di Dukuh Pekoso. Rekomendasinya, untuk meneliti di wilayah Kudus, tetangga Jepara. Hal ini menandakan bahwa kajian tentang candi atau situs yang serupa masih langka dilakukan para peneliti (Balai Arkeologi Yogyakarta, 2016). Akan tetapi artikel ini mendalami aspek toleransinya Sunan Kudus terhadap LB (sebagaimana tertuang dalam pertanyaan penelitian). Dengan demikian, naskah ini memiliki aspek kebaruan telaah bila dibanding para penulis tersebut sehingga perlu didalami.

Naskah ini untuk mengidentifikasi (1) apa saja fakta pembenar bahwa Langgar Bubrah sebagai benda cagar budaya peninggalan Hindu di Kudus Pra-Islam ?, (2) Nilai toleransi apa saja yang dilakukan Sunan Kudus terhadap Langgar Bubrah? Tujuan ditulisnya naskah ini adalah mendapatkan fakta pembenar atau fakta lain bahwa LB sebagai benda cagar budaya peniggalan Hindu di Kudus dan nilai toleransi apa saja yang dilakukan Sunan Kudus terhadap Langgar Bubrah.. Riset ini berharap memberi paparan tentang keberadaan situs dengan pendekatan ilmiah berdasarkan kajian ilmiah, tidak hanya berdasarkan kisah/cerita antar-lisan yang non-ilmiah.

\section{METODE PENELITIAN}

Artikel ini hasil riset penulis tahun 2020 yang datanya diperoleh dengan wawancara, observasi, dan kajian pustaka. Wawancara dilakukan dengan perawat LB dan observasi di lokasi Langgar Bubrah di Dukuh Tepasan, Desa Demangan, Kecamatan Kota, Kabupaten Kudus, Jawa Tengah. Data dianalisis dengan pendekatan deskriptif kualitatif. Tahapan riset ini langkahnya (1) studi prariset diawali dengan menelaah literatur tentang LB, (2) survei pendahuluan untuk mengetahui kondisi riil LB, (3) survei lapangan dan pengumpulan data dengan observasi, wawancara, literatur dan dokumentasi, (4) menyusun sistematika penulisan dengan menentukan aspek bahasan obyek studi yang diuraikan dalam bab pembahasan, dan (5) diakhiri dengan simpulan dan daftar pustaka.

\section{HASIL DAN PEMBAHASAN}

\section{Fakta Pembenar Langgar Bubrah sebagai Benda Cagar Budaya}

Desa Demangan Kecamatan Kota, Kudus terdapat 6 perdusunan, 4 RW, dan 13 RT. Desa ini berada di tengah perkotaan. Berseberangan dengan Desa Kauman, desa di mana terdapat Kawasan Menara Kudus, Masjid al-Aqsha Menara Kudus (peninggalan Sunan Kudus), Kompleks Makam Sunan Kudus. di Dukuh Tepasan, Desa Demangan merupakan lokasi LB. 
Khazanah Theologia, Vol. 3 No. 3 (2021): 171-180

Situs Hindu Pra-islam di Kudus dan Sikap Toleran Sunan Kudus

Moh. Rosyid

Mengidentifikasi peninggalan bersejarah perlu memahami kriteria benda dikategorikan benda cagar budaya (BCB). UU Nomor 11 Tahun 2010 tentang Cagar Budaya (CB) Pasal 5 kriteria benda disebut CB bila berusia dan mewakili masa gaya minimal 50 tahun, memiliki arti khusus bagi sejarah, ilmu pengetahuan, pendidikan, agama, dan/atau kebudayaan, dan bernilai budaya. Pasal 53 (1) pelestarian CB berdasarkan hasil studi kelayakan yang dapat dipertanggungjawabkan secara akademik, teknis, dan administratif, (2) pelestarian dilaksanakan oleh Tanaga Ahli Pelestarian CB (TACB). Pasal 62 pengamanan CB oleh juru pelihara dan/atau polisi khusus. Pasal 95 (1) pemerintah dan/atau pemerintah daerah bertugas melindungi, mengembangkan, memanfaatkan, meningkatkan kesadaran dan tanggung jawab bersama antara pemerintah, pemerintah daerah, dan masyarakat, (4) pemerintah dan pemerintah daerah menyediakan dana cadangan untuk penyelamatan CB.

Untuk memahami kondisi umat Hindu di Kudus pra-Islam dengan memahami karakter situs yang dimiliki oleh peninggalan Hindu. Karakter dapat berupa (1) lingga, (2) yoni, (3) pintu dalam dan luar bangunan pura (kori), (4) balai tajug (bangunan di area bagian terluar pura/setelah kori berfungsi untuk rapat keagamaan, tempat membuat sesajen, dan tempat sesajen). Keempat ciri tersebut yang ada di LB hanyalah lingga dan yoni. Langgar Bubrah jaraknya 200 m dari kawasan Kauman Menara Kudus, di Dukuh Tepasan, Desa Demangan, Kecamatan Kota. Situs budaya bersejarah (LB) memiliki kekhasan yakni ada benda budaya yakni lingga dan yoni, dua benda ini lazim adanya di candi Hindu. Perspektif arsitektur Islam, tidak lazim membangun dengan diberi lingga dan yoni karena nihil makna dalam Islam.

Bangunan kuno yang kondisinya kini sudah lapuk dindingnya dan posisi atapnya miring merupakan fakta bangunan LB terkini. Hanya saja, upaya yang dilakukan Pemda Kudus tidak sebanding dengan upaya lain yang terkait dengan pembangunan di Kawasan Kauman Menara Kudus, lokasi yang berdekatan dengan LB. Pembangunan Taman Kota, yang berdekatan dengan LB, tepatnya berada antara Masjid Madureksan (Masjid yang dibangun Sunan Kudus, sebelum membangun Masjid al-Aqsha Menara Kudus) dengan Kelenteng Hok Ling Bio. Taman tersebut didesain masa kini dengan dana APBD Kudus tahun 2015 menyebabkan sketsa Kota Lama Kudus menjadi bias karena posisi Masjid Madureksan kian terpojok posisi bangunannya dan menghilangkan sketsa pasar kuno, tradisional di Kawasan Menara Kudus. Taman Kota yang baru, desainya tidak menampakkan jejak Kudus masa lalu. Kondisi ini karena yang mendesain dan membangunnya tanpa melibatkan Dinas Kebudayaan dan Pariwisata Kudus, tetapi Dinas Pekerjaan Umum Kudus.

Ragam istilah terkait dengan nama tempat ibadah dalam Islam di Kudus, yakni masjid, musola, dan langgar. Masjid selain untuk salat Jumatan, salat lima waktu, dan aktifitas keislaman yang bernuansa budaya, seperti pembacaan sejarah Nabi Muhammad di antaranya berupa syair berbahasa Arab dalam Kitab adz-Dziba'i karya Imam al-Barzanji. Warga Kudus menyebutnya acara dziba-an atau berjanjen. Lazimnya tradisi ini dibaca di musola atau masjid dan langgar setiap Ahad malam Senin (terinspirasi atas pemahaman bahwa Nabi SAW lahirnya hari Senin 12 Rabiul Awal) atau Kamis malam Jumat (terinspirasi atas pemahaman bahwa sebaik-baik hari dalam Islam adalah hari Jumat). Adapun musala dan langgar yang membedakan dengan masjid adalah tidak digunakan untuk Jumatan. Pembeda musala dengan langgar, penyebutan musala adalah istilah bagi warga Kudus masa pasca-tahun 1980-an, sedangkan penyebutan langgar masa sebelum 1980-an. Perbedaan penyebutan ini (musala-langgar) akibat penggunaan bahasa Arab (musala, tempat salat). Musala dan langgar statusnya sama, tempat salat lima waktu dan tradisi keislaman.

Penyebutan 'langgar' pada situs Langgar Bubar merupakan bentuk penyebutan tempat ibadah dalam Islam masa lalu. Hal ini merupakan upaya 'mengambil alih' status pembuat bangunan bahwa bila menyebut langgar identik atau diidentikkan tempat salat berarti dibuat muslim masa lalu. Hanya saja, 
Khazanah Theologia, Vol. 3 No. 3 (2021): 171-180

Situs Hindu Pra-islam di Kudus dan Sikap Toleran Sunan Kudus

Moh. Rosyid

penyebutan ini perlu dievaluasi dengan adanya artikel ini yakni menyebutnya menjadi sanggar bubrah. Sanggar adalah tempat pemujaan bagi umat Hindu.

Kata bubrah dalam bahasa Jawa berarti bangunan yang belum selesai pengerjaannya karena tidak sempurna (belum jadi). Untuk memberi fakta pembenar bahwa bangunan tersebut dibuat orang Islam yang belum jadi, dituangkan dalam tradisi lisan di Kudus bahwa tatkala Pangeran Pontjowati (dikisahkan merupakan menantu Sunan Kudus) membuat LB bubrah yang rencananya semalam selesai/jadi tapi karena pada pagi buta sang pangeran mendengar suara perempuan menyapu, diduganya sudah pagi, maka dikhawatirkan ketahuan banyak orang, maka pembangunan diurungkan. Dengan kata lain bangunan tidak jadi dan tidak akan diselesaikan karena membangun semalam bila ketahuan manusia (Jawa: kamanungsan) maka tidak bijaksana dituntaskan. Kisah ini merupakan upaya melegitimasi bahwa LB karya muslim.

Padahal, hasil observasi penulis, LB merupakan bangunan yang desainnya terjadi pelapukan, bukan karena berubah (Jawa: bubrah). Fakta penguat bahwa LB adalah karya Hindu pra-Islam adalah bangunan tersebut terdapat lingga dan yoni sebagai simbol atau media berdoa hamba dengan Sang Hyang Widi Wase (Tuhan) dalam Hindu. Riset Hastutiningsih, Candi Sukuh sebagai tempat yang disucikan/disakralkan umat Hindu terdapat simbol manifestasi Dewa yang diagungkan berupa lingga dan yoni. Keberadaannya sebagai lambang Dewa Syiwa, makna lainnya sebagai perlambang kesuburan. Lingga tersebut dilingkari yoni berantai bunga, maknanya sebagai penanda pentingnya ikatan perkawinan. Selain itu, bermakna bahwa hubungan suami-isteri (persetubuhan) sesuatu yang disakralkan/disucikan. Kedua simbol (yoni dan lingga) juga berfungsi sebagai media pengobatan (Hastutiningsih, 2008). Karya Hastuti sebagai penegas bahwa lingga dan yoni menyimbolkan tempat suci bagi umat Hindu.

LB berada di pinggir jalan perkampungan yang rumah warganya lazim di pagar tembok tinggi. Masa lalu, rumah tersebut banyak yang digunakan untuk home indutry di antaranya rokok kretek dan konveksi. Jejak industri rokok masih nampak kini yakni dibuat rumah hunian atau ada yang dibuat pondok pesantren. Agar ramuannya tidak terdeteksi pesaing bisnis, maka desain rumahnya dipagar tinggi. Ada pula yang menyatakan selain itu, gadis di kawasan tersebut masa lalu, dibatasi ruang geraknya agar tidak leluasa melihat jejaka non-keluarganya. Sebagai upaya memprotek agar tidak berinteraksi secara luas yang mengkhawatirkan terjadi hubungan bebas dengan lelaki lain maka rumahnya dipagar tinggi.

Bangunan cagar budaya yang berada di atas tanah seluas $8,74 \mathrm{~m} \times 8,40 \mathrm{~m}$ persegi, panjang $6,30 \mathrm{~m}$, lebar $6 \mathrm{~m}$, tinggi 2,75 m, luas bangunan 37,80 m merupakan lahan LB. Lahan tersebut kini perlu dicek ulang. LB diprediksi dibangun tahun $932 \mathrm{H} / 1546 \mathrm{M}$ (tahun ini berdasarkan cerita lisan, bukan hasil riset arkeologi) oleh Pangeran Pontjowati, yakni Senopati (pasukan perang) Sunan Kudus. Hal yang perlu dilakukan pendalaman, kapan era Pangeran Pontjowati? Hanya saja, di kompleks Makam Sunan Kudus (di belakang masjid al-Aqsha Menara Kudus) terdapat makam yang panjang tertulis Pangeran Pontjowati, apakah dia yang membuat LB? Kajian sejarah dan arkeologi merupakan langkah ilmiah agar tidak terjadi spekulasi yang non-ilmiah.

Di LB terdapat mihrab, mihrab-nya (tempat berdoa) dalam kisah tutur di Kudus terdapat relung di dinding sebelah luar dengan hiasan bermotif tumbuhan, dinding sebelah tenggara terdapat relif lelaki yang rambutnya tertata seperti kepala Buddha dalam posisi berdiri. Hanya saja, observasi penulis tahun 2020, semua itu tidak nampak lagi, apakah karena aus dimakan waktu atau faktor lain? Di LB ada lumpang batu persegi panjang panjangnya $95 \mathrm{~cm}$, lebar $45 \mathrm{~cm}$, tinggi $35 \mathrm{~cm}$, berbentuk seperti batu pipisan (yang diduga digunakan penghalus biji-bijian, meramu jamu tradisional, atau sarana pemujaan Dewa). Ada pula batu bundar berlubang pada bagian tengahnya (berbentuk lumpang) dengan istilah lain yoni sebagai lambang kewanitaan atau lambang bumi. Kata yoni dari bahasa Sanskerta berarti bagian/tempat (simbol 
Khazanah Theologia, Vol. 3 No. 3 (2021): 171-180

Situs Hindu Pra-islam di Kudus dan Sikap Toleran Sunan Kudus

Moh. Rosyid

kandungan) untuk melahirkan anak. Kaitannya dengan batu candi, yoni berarti (pasangan lingga) sebagai simbol alat kelamin wanita (tara). Lingga dalam mitologi Hindu diibaratkan alat kelamin lelaki (phallus), lambang Siwa sebagai dewa semesta. Dalam terminologi Hindu lingga dan yoni sebagai pembangkit kundalini, maksudnya prosesi naik pada proses dan tahap yang lebih tinggi. Fungsi yoni sebagai pelengkap lingga yang melambangkan kesuburan. LB dijadikan sebagai BCB tahun 1991, di LB ada batu lingga panjangnya $125 \mathrm{~cm}$, luas lingkaran $155 \mathrm{~cm}$, tinggi $125 \mathrm{~cm}$, bergaris tengah $45 \mathrm{~cm}$ sebagai lambang Dewa Siwa, simbol kesatuan abadi atau Dewa yang tidak berbentuk. Dalam kajian ini, lingga lebih mendekati bila diberi makna titik tugu pemujaan dewa, sedangkan yoni didefinisikan sebagai organ kandungan yang melahirkan Brahmana dan dewa lainnya. Berarti pula perwujudan arca, manifestasi dewa, bentuk ikon Siva. Di kompleks LB terdapat yoni panjangnya $200 \mathrm{~cm}$, lebar $35 \mathrm{~cm}$, tinggi $15 \mathrm{~cm}$, luas tanah $74 \mathrm{~m}$ persegi, dan luas bangunan $10 \mathrm{~m}$. Diprediksi pada abad ke-14 M. Pada bagian pilar bawah terdapat relief patung Dewa Siwa berdiri memegang senjata trisula. Diperkirakan, sebelum didirikan LB, telah didirikan candi Hindu (Supani, 2009). Dalam prediksi penulis pun karena kisah tersebut dalam hal pembuat dan tahun pembuatan tidak berdasarkan kajian arkeologi tapi cerita rakyat, dapat diprediksi bangunan semula peninggalan Hindu yang tak terawat. Dalihnya, yoni dan lingga dalam Islam tidak tertradisi. Dengan demikian, yang urgen dilakukan adalah riset berbasis arkeologi. Riset arkeologi dengan tiga tahapan menurut arkeolog, Mundardjito yakni pengumpulan data, data dianalisiadan direkonstruksi kemudian dibuat laporan atau publikasi hasil kedua tahapan tersebut. Pengumpulan data dengan teknik dengan penjagaan (untuk mengetahui keutuhan data arkeologi, survei permukaan tanah, bawah tanah, potret udara, eskavasi lubang uji (test-pit) dan wawancara; eskavasi dengan teknik spit, lot, lapisan tanah (layer) atau teknik lain yakni sedot dan lapis demi lapis (untuk eskavasi obyek di bawah air). Teknik pengumpulan datanya berdasarkan sifat, kontur, dan kondisi lapangan. Hasil pengumpulan data (1) artefak (benda dari alam yang dimodifikasi oleh peneliti (sebagian atau seluruhnya), (2) ekofak (benda dari alam yag diduga oleh peneliti termanfaatkan oleh manusia), (3) fitur (artefak yang tak dapat diangkat dari tempat semula). Pada tahap survei dan eskavasi juga dilakukan perekaman data berupa catatan, gambar, peta, foto, dan vidio pada artefak, ekofak, dan fitur dan lingkungan sekitar obyek riset (situs). Setelah itu, mengolah data dengan (1) mengklasifikasi sejak tahap awal bahwa artefak dan ekofak terkumpul dan dibersihkan, dicatat proses penemuannya, difoto/digambar, diklasifikasi awal berdasar kategori artefak, ekofak, dan hasil perekaman data. Dalam merekam data, langkahnya, penomoran dan penginventarisasin berdasarkan kategori, pengkatalogisasian dan pemilahan berdasarkan kategori, dan penyimpanan berdasarkan kategori. Setelah itu, analisis dan rekonstruksi, dan pelaporan (Mundardjito, 1999). Dapat pula melakukan penelitian arkeologi dengan empat langkah yakni surveys, excavations, archival research, and oral history interviews. Survei permukaan dilakukan agar mendapatkan artefak, keadaan geofisika dan topografinya. Eskavasi dilakukan untuk membuktikan dan menemukan jejak masa lalu dari artefak yang terkubur dalam tanah. Arsip masa lalu sebagai sumber yang tercatat atau tersimpan sebagai tulisan sejarah dan peta dan foto kuno untuk digunakan menganalisa dan menginterpretasi. Wawancara sejarah lisan untuk mendapatkan data pribadi atau kelompok sosial dalam ingatan saksi atau pelaku sejarah atas komunitas tertentu (Cassela, 2005). Hanya saja, terkait LB, yang lebih diutamakan adalah langkah eskavasi dari artefak yang terpendam dalam tanah.

Ada empat tahap penggolongan data dan analisis datanya dalam mencari makna simbolik di balik wujud fisik situs budaya, pertama, mengidentifikasi persamaan dan perbedaan fisik bangunan. Hal ini dilakukan dengan cara membandingkan dengan situs serupa. Hanya saja di Kudus belum penulis temukan situs serupa. Kedua, memperinci fakta pembeda yang ada. Membedakan dalam konteks ini tidak terlaksana karena tidak adanya situs pembanding. Ketiga, memberi konteks sosial tertentu pada data yang 
Khazanah Theologia, Vol. 3 No. 3 (2021): 171-180

Situs Hindu Pra-islam di Kudus dan Sikap Toleran Sunan Kudus

Moh. Rosyid

ada. Konteks sosial kehidupan umat Hindu di Kudus pra-Islam belum banyak penulis temukan refensi sejarahnya. Keempat, menginterpretasikan agar diperoleh kejelasan makna simboliknya. Interpretasi sangat tergantung keberadaan poin pertama hingga ketiga yang tidak/belum ditemukan. Dengan demikian, empat tahap penggolongan dan analisaa tersebut memerlukan kerja ekstra bagi arkeolog dan sejarawah menggalinya dengan ragam sumber. Hanya saja,

Dengan upaya versi Mundardjito yang lebih mudah dilakukan sehingga diperoleh jawaban atas pertanyaan apa fakta pembenar secara ilmiah bahwa LB sebagai situs Hindu. LB kategori cagar budaya (CB) berdasarkan Surat Keputusan Pusat Pelestari Purbakala Nomor 988/02.SP/BP3/P.IX/2006 sehingga menjadi warisan budaya yang bersifat kebendaan.

\section{Sikap Toleran Sunan Kudus terhadap Peninggalan Hindu di Kudus Pra-Islam}

Hal utama yang mendasari atau yang menjadi bahan pertimbangan diterbitkannya UU Nomor 5 Tahun 2017 tentang Pemajuan Kebudayaan adalah upaya yang padu antara pemerintah, pemda, beserta masyarakat melestarikan cagar budaya. Pertimbangan utama UU (1) pemajuan kebudayaan untuk investasi nasional, (2) identitas kebudayaan nasional, (3) butuh dilindungi, dikembangkan, dimanfaatkan, dan dibina untuk terwujudnya bangsa yang berdaulat. Konteks Kudus, di antaranya berupa bangunan kuno, yakni LB.

Atas dasar pijakan tersebut, upaya menyelamatkan objek budaya (amanat Pasal 26 (1) UU Nomor 5 Tahun 2017) sebuah keharusan dan sifatnya mendesak. Pertama, restorasi yakni mengembalikan/memulihkan obyek pemajuan kebudayaan ke keadaan semula (Pasal 26 ayat 3 poin c). Kondisi LB kini sangat memprihatinkan struktur dan kondisi fisiknya, mengapa? tidak mendapat perhatian perawatan secara periodik dan rutin oleh Pemkab Kudus c.q Dinas Kebudayaan dan Pariwisata. Fakta pembenarnya, tidak ada alokasi anggaran perawatan meski telah dibentuk tim ahli cagar budaya (TACB). Kondisi atapnya miring, pernik hiasan dinding memudar karena cuaca. Padahal, sebagian warga di Kudus ada yang masih memanfaatkannya untuk media berdoa dalam mengawali bila warga memiliki hajat (menantu, mengkhitankan, mendirikan rumah, dsb.). Warga di sekitar LB-pun tidak nampak peduli merawatnya. Kedua, revitalisasi yakni menghidupkan kembali obyek pemajuan kebudayaan yang nyaris musnah. Anggota DPRD Kudus harus pula dilibatkan aspek politik penganggaran APBD Kudus agar ada keberpihakan terhadap cagar budaya. Wujud riilnya menyediakan dana perawatan cagar budaya dengan dasar dan pertimbangan investasi di bidang budaya dan destinasi wisata sejarah (Pasal 47 UU Nomor 5 Tahun 2017). Apabila upaya tersebut terwujud, LB tidak rusak, maka memberi pemahaman pada generasi kini dan mendatang bahwa Sunan Kudus menanamkan jejak toleran terkait LB. Wujud toleransinya dengan tidak mengubah desain bangunan kuno tersebut.

Kata toleran atau toleransi secara sederhana adalah upaya seseorang atau sekelompok orang yang sikapnya dalam berinteraksi tidak memusuhi pihak lain yang berbeda agama atau seagama tapi berbeda aliran (Abdullah, 2018; Arifianto, 2021; Ghazali, 2016). Analisa Santosa dan Yudi, sikap toleransi Sunan Kalijaga dalam berdakwah di Pulau Jawa dengan keberadaan umat Hindu-Buddha diwujudkan dengan dakwah nonfrontal tapi toleran dengan budaya lokal. Pola yang digunakan mengikuti sambil mempengaruhi budaya setempat secara bertahap sehingga ajaranIslam dapat dipahaminya (Santosa \& Armansyah, 2013). Menurut Fadli, sikap toleran dilakukan Walisongo, pendakwah di Jawa di antaranya dengan media wayang dan masjid (Fadli, 2020). Wujud toleransi menurut Ridho dan Thibburruhany dipilah menjadi tiga bentuk (1) keterlibatan aktif dalam membangun peradaban bersama, (2) menerima dengan baik golongan lain, dan (3) mengenal secara mendalam atas diri orang lain berkonsekuensi mengakui sepenuhnya nilai dari kelompok lain (Ridho \& Thibburruhany, 2019). Konteks toleransi 
Khazanah Theologia, Vol. 3 No. 3 (2021): 171-180

Situs Hindu Pra-islam di Kudus dan Sikap Toleran Sunan Kudus

Moh. Rosyid

terhadap bangunan diwujudkan dengan tetap melestarikan karya umat agama lain, tidak merusak, mengubah atau menghilangkan. Bila dikaitkan dengan konsep Ridho dan Thibburruhany kategori toleransi penerimaan dengan baik atas golongan lain. Lazimnya, kajian tentang toleransi didominasi bentuk interaksi sosial antar-umat beragama atau seagama berbeda aliran yang nirkoflik. Konteks LB toleransinya adalah sikap tokoh agama menghadapi karya budaya umat agama yang lain yang tetap menjaganya. Sikap serupa dilakukan Sunan Kudus dengan tidak mengubah, merusak, dan menghilangkan dua gapura (istilah bagi umat Hindu adalah kori) di serambi dan di dalam Masjid al-Aqsha Menara Kudus hingga kini. Kedua gapura/kori kategori benda cagar budaya, selain Menara Kudus yang berada di halaman Masjid al-Aqsha. Jarak antara Masjid al-Aqsha dengan LB kurang lebih $1 \mathrm{~km}$ yang berada dalam satu kawasan Kota Kudus Kuno (ada yang menyebut Kawasan Kudus Kulon). Hanya dipisahkan oleh Taman Beringin yang berada di tengah-tengah antara Masjid Madureksan (dibangun lebih dulu oleh Sunan Kudus daripada Masjid al-Aqsha) dengan Kelenteng Hok Ling Bio. Upaya Sunan Kudus tersebut pada dasarnya melakukan hakikat bertoleransi. Hakikat toleransi menurut Zulyadin adalah usaha kebaikan atas kemajemukan agama yang bertujuan tercapainya kerukunan intern dan antar-umat beragama. Mengakui eksistensi suatu agama bukanlah mengakui kebenaran ajaran agama (Zulyadin, 2018).

Konteks toleran Sunan Kudus yang dikaji dalam naskah ini yakni tidak melakukan pemusnahan situs budaya masa Hindu di Kudus pra-Islam. Sikap ini mengedepankan kearifan lokal yang dimiliki Sunan Kudus. Menurut Pangalila dan Jeane, sikap toleran dapat dipupuk pada masa kini dengan mengedepakan kearifan lokal sebagaimana terjadi di Kota Tomohon Sulawesi Utara yang berbekal kearifan lokalnya terwujud toleran antar-umat beragama yakni si tou timou tou (manusia hidup untuk memanusiakan orang lain), mapalus (gotong-royong), dan torang samua basudara (kita semua bersaudara) (Pangalila \& Mantiri, 2020). Hanya saja, dilihat dari aspek penamaan situs terjadi perubahan yang semula (diduga) bernama sanggar menjadi langgar. Kata sanggar identik dengan tempat pemujaan atau candi. Dugaan perubahan tersebut diperkuat adanya kekhasan sebuah bangunan yang memiliki ornamen atau benda yang ada di candi yakni lingga dan yoni. Kedua benda tersebut hingga kini masih utuh dan berada di area cagar budaya LB. Penamaan tersebut, hemat penulis oleh generasi pasca-Sunan Kudus dengan mempertimbangkan hal tertentu yang perlu pendalaman pada topik lain. Untuk menanamkan sikap toleransi, di tengah kondisi riil perubahan nama tersebut, langkah yang dilakukan generasi di Kudus masa kini berpijak pada konsep pendidikan multikultur. Menurut Sofi'i dengan menanamkan sikap menghormati martabat manusia agar tercipta kedamaian tanpa manipulasi dan tidak direkayasa (Sofi'i, 2019).

Hal yang memprihatikan, kini kodisi Langgar Bubrah areanya kian terdesak oleh pelebaran halaman oleh penghuni rumah di sekitarnya. Fakta ini dapat dikroscek dengan foto Langgar Bubrah era kolonial Belanda yang tidak sesempit areanya sebagaimana kini. Agar 'tuduhan' ini tak menjadi hoax, Pemkab Kudus harus bekerja sama dengan Badan Pertanahan Nasional Kabupaten Kudus untuk melakukan ceking sertifikat lahan penghuni. Hal ini sebagai upaya untuk memperoleh kepastian status lebar dan luasnya lahan Langgar Bubrah. Hal pokok yang harus dilakukan adalah melakukan upaya pendekatan yang arif dan santun untuk mengurangi ketersinggungan pemilik lahan. Bila hal ini terlaksana, langkah selanjutnya adalah Pemda memerlukan kepedulian merawat dengan dana yang ideal dari APBD Kudus. Merawatnya berdasarkan kalkulasi Tim Ahli Cagar Budaya (TACB) yang telah dibentuk oleh Bupati Kudus tahun 2019 dan bekerja sama dengan Tim Balai Pelestarian Cagar Budaya Provinsi (BPCB) Jawa Tengah. Kondisi bangunan Langgar Bubrah yang makin tua hingga kondisi bangunannya miring, hiasan dan ornamennya kian pudar akibat termakan cuaca perlu perbaikan. Merawatnya harus merujuk pada 
UU Nomor 11 Tahun 2010 tentang Cagar Budaya (CB) dan UU Nomor 5 Tahun 2017 tentang Pemajuan Kebudayaan. Bentuk toleran Sunan Kudus konteks bangunan Langgar Bubrah adalah masih dilestarikannya lingga dan yoni di LB hingga kini. Intensifnya mengkaji dinamika LB akan mengembangkan kajian tentang peninggalan Hindu pra-Islam di Kota Kudus.

\section{SIMPULAN}

Lestarinya situs Hindu di Kota Kudus khususnya berupa yoni dan lingga di LB sebagai fakta bahwa Sunan Kudus hadir di Kudus telah ada situs tersebut dan tidak memusnahkannya sebagai wujud toleran. Pesan toleran perlu diikuti jejaknya oleh generasi di Kudus masa kini dan mendatang. Pemerintah Kabupaten Kudus harus pula merawatnya karena kondisi fisik LB kini tidak lagi utuh akibat cuaca. Merawat benda cagar budaya yang memiliki nilai sejarah harus dilakukan oleh tim ahli cagar budaya (TACB). Perawatan BCB memerlukan kiprah politisi dalam hal anggaran yakni memihak benda bersejarah dalam wujud penganggaran agar dapat dijadikan alternatif utama destinasi wisata sejarah yang memiliki pesan toleransi. Lingga dan yoni sebagai ciri peninggalan Hindu, di Kudus satu-satunya yang masih utuh hanyalah di LB sehingga merawatnya oleh warga setempat, masyarakat Kudus, DPRD Kudus dan Pemda Kudus sebagai sebuah keniscayaan.

\section{REFERENSI}

Abdullah, A. (2018). Wajah Toleransi Dan Perdamainan Dalam Kontestasi Historisitas. Religious: Jurnal Studi Agama-Agama Dan Lintas Budaya, 2(2), 107-126.

Anisa. (2017). Keterkaitan Aktivitas Ekonomi dengan Tata Ruang Rumah Tradisional Kudus di Kota Lama Kudus. Seminar Nasional Sains Dan Teknologi 2017 Fakultas Teknik Universitas Muhammadiyah Jakarta.

Arifianto, Y. A. (2021). Menumbuhkan Sikap Kerukunan dalam Persepektif Iman Kristen Sebagai Upaya Deradikalisasi. Khazanah Theologia, 3(2), 93-104.

Balai Arkeologi Yogyakarta. (2016). Eksplorasi Tinggalan Arkeologi di Lereng Utara Gunung Muria. Yogyakarta: Balai Arkeologi Yogyakarta.

Cassela, E. C. (2005). Social Workers: New Directions in Industrial Archeology. In I. J. Symonds (Ed.), Industrial Archeology: Future Directions (pp. 3-32). Washington DC: Springer Science and Business Media Inc.

Fadli, F. (2020). Media Kreatif Walisongo dalam Menyemai Sikap Toleransi antar-umat Beragama di Jawa. Al-Tadzkiyah Jurnal Pendidikan Islam, 10(2), 287-302.

Ghazali, A. M. (2016). Toleransi beragama dan kerukunan dalam perspektif Islam. Religious: Jurnal Studi Agama-Agama Dan Lintas Budaya, 1(1), 25-40.

Hastutiningsih, T. (2008). Simbol-Simbol Agama Hindu di Candi Sukuh (Studi Simbol Agama Hindu di Dusun Sukuh, Kecamatan Ngargoyoso, Kabupaten Karanganyar. UIN Sunan Kalijaga.

Himawan, U. (2012). Langgar Bubrah, sebuah Akulturasi Hindu-Islam. Retrieved 16 January 2021, from Gangsiput.com website: https://gangsiput.com/2012/07/08/langgar-bubrahsebuah-akulturasi-hindu-islam/

Mundardjito. (1999). Metode Penelitian Arkeologi. Jakarta: Depdiknas.

Pangalila, T., \& Mantiri, J. (2020). Nilai Budaya Masyarakat Sulawesi Utara sebagai Model Pendidikan Toleransi. Jurnal Ilmiah Mimbar Demokrasi, 20(1), 55-64.

Ridho, A., \& Thibburruhany. (2019). Prinsip Toleransi Beragama sebagai Pondasi Membangun Peradaban Islam di Era Modern. El-Afkar, 8(1), 75-94.

Roesmanto, T. (2013). Rupa Bentuk Menara Masjid Kudus, Bale Kulkul, dan Candi. Jurnal Arsitektur, $4(1), 28-35$. 
Khazanah Theologia, Vol. 3 No. 3 (2021): 171-180

Situs Hindu Pra-islam di Kudus dan Sikap Toleran Sunan Kudus

Moh. Rosyid

Santosa, \& Armansyah, Y. (2013). Prinsip Toleransi Sunan Kalijaga dan Kontribusinya dalam Islamisasi di Jawa. Konstekstualita, 28(1), 34-46.

Sofi'i, I. (2019). Pendidikan Multikultural suatu Telaah Kritis terhadap Toleransi Keberagamaan dalam Harmonisasi Sosial. Prosiding Seminar Nasional, Harmonisasi Keberagaman Dan Kebangsaan Bagi Generasi Milenial. Lembaga Kajian Keagamaan Universitas Pamulang.

Supani, S. D. (2009). Benda Cagar Budaya Peninggalan Sejarah dan Purbakala Kabupaten Kudus. Kudus: Dinas Kebudayaan dan Pariwisata Kudus.

Supatmo. (2014). Keunikan Ornamen Bermotif Figuratif pada Kompleks Bangunan Masjid Menara Kudus. Imajinasi: Jurnal Seni, 7(1), 63-80.

Zulyadin. (2018). Penanaman Nilai-Nilai Toleransi Beragama pada Pembelajaran Pendidikan Agama Islam. Al-Riwayah: Jurnal Kependidikan, 10(1), 123-149. 